\title{
Composite Structural Analysis of a High Altitude, Solar Powered Unmanned Aerial Vehicle
}

\author{
Ahmad Alsahlani and Thurai Rahulan \\ School of Computing, Science \& Engineering, University of Salford,Greater Manchester, United Kingdom \\ Email: ahmad.alsahlani@gmail.com; t.rahulan@salford.ac.uk \\ Nathera Abdulhassan \\ Department of Mechanical Engineering, Basrah University, Basrah, Iraq \\ Email: nathera1971@yahoo.com
}

\begin{abstract}
$\bar{A}$ bstract-In this paper, a development of a low order composite structure module has been introduced. This module can design the wing structure for the given aerodynamic load. The wing structure is broken down into non-spar elements and spars. The weight of non-spar elements are estimated by using empirical equations that were used by NASA for solar powered high altitude UAVs. The Spar is sized by using a numerical approach, which is developed in this paper. The spar is modelled as a composite rectangular wing-box and assumed to withstand the entire load with no contribution from the secondary wing components. The required numbers of laminate on each side of the spar are found iteratively until no failure or buckling is detected. The orientation of laminate of each side of spar was inspired by the existing high altitude aircraft structure. A linear finite beam element is used to evaluate the wingbox deflection under the internal and the aerodynamic loads while only a quasi-static equilibrium is considered during the sizing process. The module has been written in MATLAB. This tool can be used either in the conceptual design stage or in an optimisation process because it facilitates rapid computation. This module has been validated with a high order commercial package (ANSYS). The deflection calculation shows excellent agreement with less than $0.25 \%$ error. The stress calculations show a reasonable agreement with ANSYS with maximum error margin of about $4 \%$ at the maximum shear stress level. However, this amount of error could be unimportant as a high factor of safety is usually taken in the design of composite structures. The weight prediction function also has been validated using reference to a NASA Pathfinder aircraft. The predicted weight seems reasonable with a $1.6 \%$ difference from the expected weight of the case study.
\end{abstract}

Index Terms - composite structure, high altitude aircraft, UAV weight estimation, solar powered UAV

\section{INTRODUCTION}

High-altitude long endurance unmanned aerial vehicles (HALE-UAV) flying in the stratosphere can provide a useful platform for sensors to support a range of military and civilian surveillance tasks. HALE-UAVs are characterized by a high aspect ratio wing resulting in very flexible airframe. The real physical structure of aircraft

Manuscript received April 9 2016; revised November 28, 2016. needs to be simplified if structural design considerations are to be included in the optimisation process. The purpose of such an optimisation is to find a minimum feasible weight solution, subject to certain criteria. Weight reduction can result in increased payload capability and reduced fuel requirement. Nowadays, composite materials have been largely used in the aircraft structure due to their higher stiffness to weight ratio. For instant, Helios, Pathfinder, Qinetiq Zephyr and X-HALE and most other high altitude UAV are based on lightweight carbon fibre construction. Modelling or simplifying the wing structure is often desired at preliminary stage of design. In the research activity, a great deal has been undertaken for using composite rectangular or circular cross section beam and thin plate to mimic or build the wing structure and to study its strength and deflection against static and dynamic loads. For instance, a rectangular cross-section wing-box was used in the Michigan University prototype (XHALE) [1] while a circular section beam is used in most of the high altitude NASA prototypes such as the Helios and the Pathfinder [2]. For such types of aircraft, little research activity can be found to design and simulate the wing structure using low order analysis at the preliminary design stage implemented with weight prediction and failure considerations. For example, Olivier \& Laurent [3] proposed an analytical mass equation to be implemented in the optimisation tool to find the minimum number of plies for the wing-box, required to prevent the failure under critical loads. The buckling failure was not taken into account but a certain minimum number of plies was adopted to prevent buckling. Another limitation of this model is that the wing-box is sized according to the load concentrated on the root section, which means that the majority of the wing box could be over-designed. The main target in this paper is to build a low order Composite Structure Module (CSM) to size the wing and to estimate its weight for a solar powered high altitude UAV considering the failure and buckling of the laminate.

\section{COMPOSITE WING SIZING APPROACH}

The wing structure can be broken down into non-spar elements and spars. Non-spar elements are estimated using empirical equations while the spars are sized using a 
numerical approach, which is introduced in this paper. The spars (wing-box) are modelled as a composite thin walled beam and assumed to withstand the entire load with no contribution from secondary wing components. The typical wing cross section of solar powered UAVs is shown in Fig. 1.

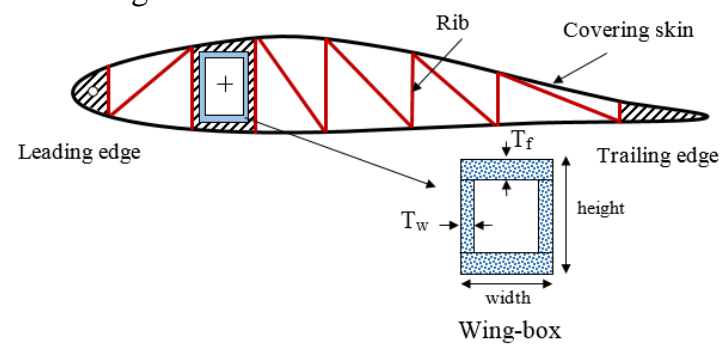

Figure 1. Sketch of the structural wing model and wing-box idealization

\section{A. Non-spar Elements Estimation}

The mass of the non-spar elements such as the leading edge, the trailing edge, the covering skin, the ribs, and the control systems will be estimated by using empirical equations that were been published by NASA Langley Research Centre and Lockheed corporation for high altitude solar powered platform [4]. These are dependent on the aircraft Aspect Ratio $(A R)$, wetted area $\left(S_{\text {wet }}\right)$, and wing area $(S)$ as in the following equations given in references [4], [5]:

Leading edge mass:

$$
\mathrm{m}_{\mathrm{le}}=0.9415 \mathrm{~S} / \mathrm{AR}^{0.5}
$$

Trailing edge mass:

$$
\mathrm{m}_{\mathrm{te}}=0.0998(\mathrm{AR} \mathrm{S})^{0.5}
$$

Covering mass:

$$
m_{\text {cov }}=\left(0.2055+0.0028(A R / S)^{0.5}\right) S_{\text {wet }}
$$

Ribs mass:

$$
m_{\text {rip }}=1.033 S^{0.6}
$$

Control systems mass:

$$
m_{\text {cont }}=0.3006 S / A R^{0.5}
$$

\section{B. Spars Sizing Approach}

The spar which is the main wing-box structural element should be designed to withstand the majority of the loads including the aerodynamic forces and inboard weight. The wing-box will be discretised into variant stations. Then, each station will be sized according to the maximum bending moment, shear force, and torsion moment exerted on the station. The load which is used in the sizing process should be the critical load (the worst load expected in the flight diagram). Moreover, the allowable stress or strain in each ply must be defined and usually can be signed by knowing the ply's ultimate stresses or strains from its mechanical properties with a safety margin represented by a factor of safety [6], [7]. Spars sizing approach based on suggesting a number of laminate in each wing-box side (in each station), which is stacked in a way inspired by the existing HALE UAVs. It is an iterative way where the number of plies will be increased during the iterations till no failure or buckling is encountered. Since the number of laminates are known, the wing-box weight can be evaluated and this value which is effectively inertia relief will be added to the overall loading condition and the calculation will be repeated until convergence is achieved. A linear finite beam element is used to evaluate the wingbox deflection under the internal and the aerodynamic loads while only a quasi-static equilibrium is considered during the sizing process. Overview of the methodology is shown in Fig. 2. The Tornado VL code has been used to evaluate the aerodynamic loads. A MATLAB code has been written to discretise the wing-box and size it according to this methodology.

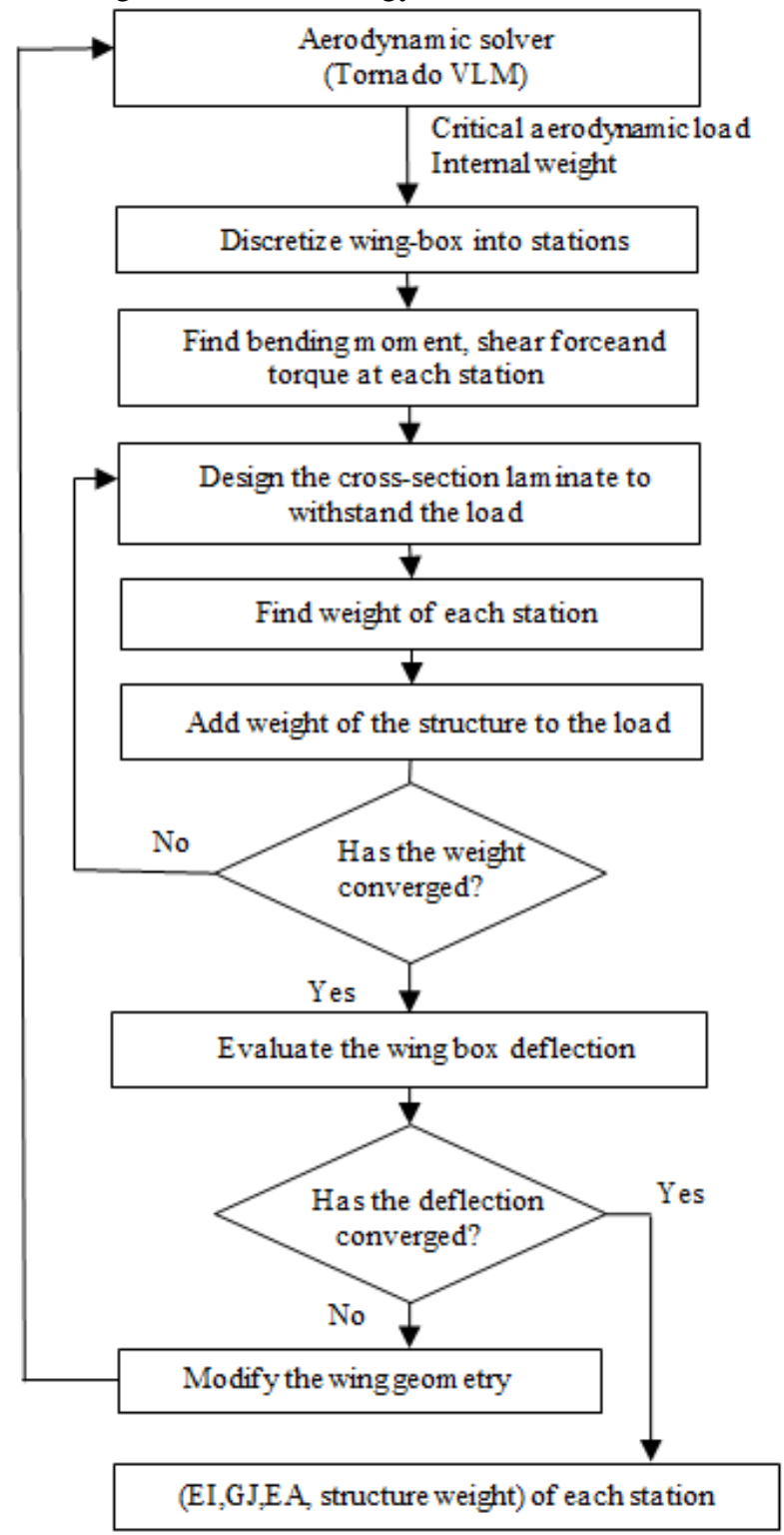

Figure 2. Overview of the wing-box sizing methodology

\section{Wing-Box Cross-Section Design}

Fig. 3-A shows the load distribution within composite rectangular cross-section under three types of loading. In the case of pure shear loading, it is clear to appreciate that the maximum shear flow occurs at the mid-points of the two webs while the flanges have the highest shear flow at their ends. The shear flow under pure torsional load is constant at any position within the cross section. The 
direct stress under pure bending usually varies from ply to ply depending on its own directional stiffness modulus, but generally for any ply, the stress distribution is linearly proportional to the distance between a point which lies on the ply and the neutral axis [6]-[8]. It is concluded that, theoretically, there are three critical zones (in each quarter) where the failure will occur first as indicated in Fig. 3-B. Therefore, only these zones will be examined against the failure criterions. Initially, a number of symmetric plies will be assumed for each flange and different symmetric plies for each web, as shown in Fig. 4. Each ply in the section has the same mechanical properties and thickness, but with different orientation angles. The outer dimensions and external forces (lift, torsion, and other internal weights) are given by the wing configuration and its critical aerodynamic performance by the Tornado VL. The target here is to find the minimum number of plies required in each web and flange at each station.

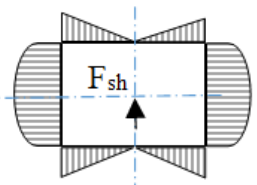

Shear flow distribution under pure shear force

A-Load distribution with three type of loading

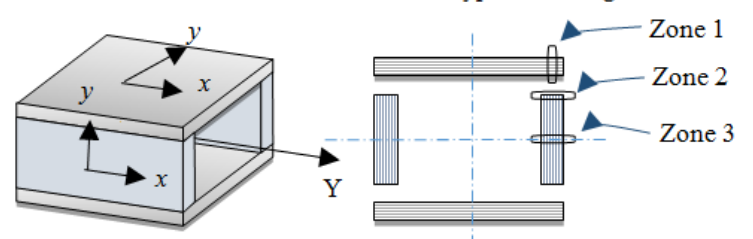

B-Critical zones in the cross section

Figure 3. Wing-box cross section loading Flanges plies $\left\lceil\mathrm{N}_{0} \ldots . .00 \quad \mathrm{~N}_{45} \ldots .45-45\right\rceil_{\mathrm{s}}$

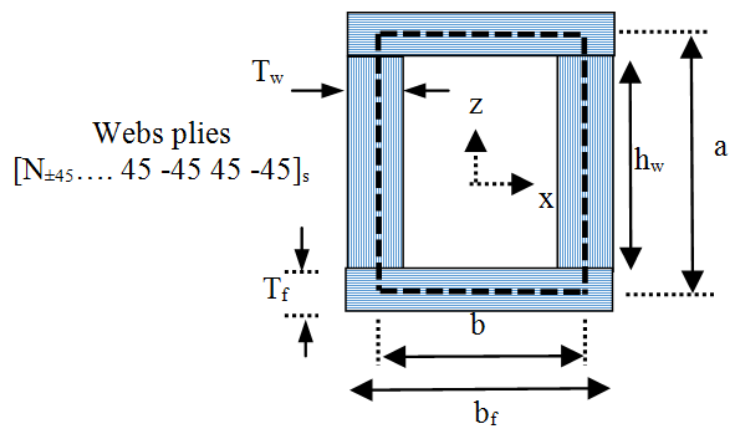

Figure 4. Wing box cross section

The shear load is a maximum in the webs and hence \pm 45 plies will be used while a number of \pm 45 and 0 plies will be used in the flanges. These plies will be stacked symmetrically about the axis lying in the middle of the flanges. An identical procedure can be argued when considering each web.

The following steps can be taken to design a wing-box cross-section for given dimensions and load to evaluate the principle stresses and the mechanical properties of the cross-section:
1. Assume symmetrical plies stacking in each element such as in Fig. 4.

2. Evaluate the lamina stiffness matrix for each ply in the cross section and transform it to the system coordinate [9].

3. Evaluate the Young's modulus of each ply $\left(E_{y_{p l y}}\right)$ in the appropriate directions.

4. Evaluate the stiffness values of the $(A B D)_{\text {web }}$ and the $(A B D)_{\text {flange }}$ matrices in addition to their matrix inverses $\left((a b d)_{\text {web }}\right.$ and $\left.(a b d)_{\text {flange }}\right)$ considering each element as a laminated plate such as in Fig. 5. Hence the resultant forces and moments on the laminated plate can be written as:

$$
\left|\begin{array}{c}
N_{x} \\
N_{y} \\
N_{x y} \\
M_{x} \\
M_{y} \\
M_{x y}
\end{array}\right|=\left|\begin{array}{llllll}
A_{11} & A_{12} & A_{16} & B_{11} & B_{12} & B_{16} \\
A_{12} & A_{22} & A_{26} & B_{12} & B_{22} & B_{26} \\
A_{16} & A_{26} & A_{66} & B_{16} & B_{26} & B_{66} \\
B_{11} & B_{12} & B_{16} & D_{11} & D_{12} & D_{16} \\
B_{12} & B_{22} & B_{26} & D_{12} & D_{22} & D_{26} \\
B_{16} & B_{26} & B_{66} & D_{16} & D_{26} & D_{66}
\end{array}\right|\left|\begin{array}{c}
\epsilon_{x}^{0} \\
\epsilon_{y}^{0} \\
\gamma_{x y}^{0} \\
k_{x} \\
k_{y} \\
k_{x y}
\end{array}\right|
$$

where: $[\epsilon]$ and $[k]$ are the mid-plane strains and the curvatures of the laminate, $A_{i j}$ : the laminate extensional stiffness, $B_{i j}$ : the laminate coupling stiffness, and $D_{i j}$ : the laminate bending stiffness. The above equation can now be written as:

$$
\left|\begin{array}{c}
\epsilon_{x}^{0} \\
\epsilon_{y}^{0} \\
\gamma_{x y}^{0} \\
k_{x} \\
k_{y} \\
k_{x y}
\end{array}\right|=\left|\begin{array}{llllll}
a_{11} & a_{12} & a_{16} & b_{11} & b_{12} & b_{16} \\
a_{12} & a_{22} & a_{26} & b_{12} & b_{22} & b_{26} \\
a_{16} & a_{26} & a_{66} & b_{16} & b_{26} & b_{66} \\
b_{11} & b_{12} & b_{16} & d_{11} & d_{12} & d_{16} \\
b_{12} & b_{22} & b_{26} & d_{12} & d_{22} & d_{26} \\
b_{16} & b_{26} & b_{66} & d_{16} & d_{26} & d_{66}
\end{array}\right|\left|\begin{array}{c}
N_{x} \\
N_{y} \\
N_{x y} \\
M_{x} \\
M_{y} \\
M_{x y}
\end{array}\right|
$$

5. Evaluate the equivalent membrane elastic constant for each element (webs and flanges) by using the following equations [7]:

$$
\begin{aligned}
& E_{x i}=1 /\left(t a_{11}\right)_{i} \\
& E_{y i}=1 /\left(t a_{22}\right)_{i}
\end{aligned}
$$

where $t$ is the element thickness; $t=T_{f}$ for flange and $t=T_{w}$ for web as in Fig. 4 .

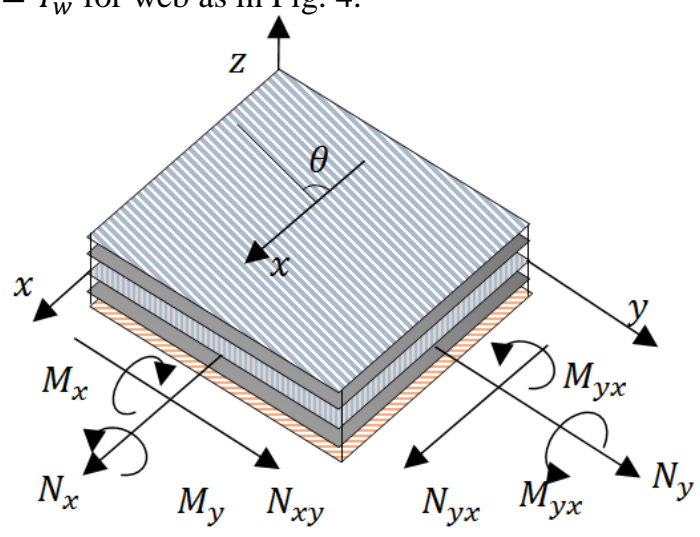

Figure 5. Coordinate system, resultant forces and moments for laminated plate

6. Evaluate the equivalent $E I_{y}$ of the cross-section (known as the overall section second moment of area because the Young's modulus value is varied from element to element depending on laminate configuration) [7], [9]. 


$$
E I_{y}=\int E_{x} z^{2} d A=\sum_{i=1}^{n_{e}}\left(E_{x} I_{y y}\right)_{i}
$$

where $n_{e}$ is the number of elements ( 2 webs and 2 flanges $=4), I_{y y}$ is the element second moment of area about y axes.

7. Find the bending stress in each ply of each flange and in the top/bottom plies at the webs using the following equation[9]:

$$
\sigma_{x_{p l y}}=M_{x} z \frac{E_{x p l y}}{E I_{y}}
$$

8. Evaluate the principal stresses in each ply of each flange and the top/bottom ply of each web due to the bending load, the shear force, and the torque individually using the principal stress equations given by:

$$
\begin{gathered}
\sigma_{1}=\sigma_{x} \cos ^{2} \theta+\sigma_{y} \sin ^{2} \theta+2 \tau_{x y} \cos \theta \sin \theta \\
\sigma_{2}=\sigma_{x} \sin ^{2} \theta+\sigma_{y} \cos ^{2} \theta-2 \tau_{x y} \cos \theta \sin \theta \\
\tau_{12}=\left(\sigma_{y}-\sigma_{x}\right) \cos \theta \sin \theta+\tau_{x y}\left(\cos ^{2} \theta-\sin ^{2} \theta\right)
\end{gathered}
$$

9. Sum the effects of the bending, the shear and the torque loads for those plies lying in the critical zones.

10. If failure is detected in a ply, add additional number of plies in the failed elements and repeat the calculation above (step 4). The maximum failure criterion can be used as below with the ply coordinate [7]:

$$
\begin{gathered}
\sigma_{1} \leq \frac{X_{t}}{F o S}, \quad \sigma_{2} \leq \frac{Y_{t}}{F o S} \\
\left|\sigma_{1}\right| \leq \frac{\left|X_{c}\right|}{F o S}, \quad\left|\sigma_{2}\right| \leq \frac{\left|Y_{c}\right|}{F o S} \\
\tau_{12} \leq \frac{\mathrm{S}}{F o S}
\end{gathered}
$$

where $F o S$ is the factor of safety, $\mathrm{X}_{\mathrm{t}}, \mathrm{Y}_{\mathrm{t}}, X_{c}, \mathrm{Y}_{\mathrm{c}}$ and $\mathrm{S}$ are the maximum strength values in longitudinal tension, in transverse tension, in longitudinal compression, in transverse compression and in inplane shear respectively.

11. Check whether buckling failure is detected in each web and flange by evaluating the buckling load and the exerted load on the web. If buckling occurs in any element, increase the number of plies in the failed element and repeat the calculation (from step 4). The buckling criterion can be written as:

$$
\begin{aligned}
N_{x} & <N_{x_{\text {buckling }}} \\
N_{x y} & <N_{x y_{\text {buckling }}}
\end{aligned}
$$

where $N_{x}, N_{x y}$ are the axial and the shear forces respectively in the web, $N_{x_{\text {buckling }}}, N_{x y_{\text {buckling }}}$ are the critical buckling axial and the shear forces respectively. The critical buckling loads can be evaluated by the following equations [10], [11]:

For webs:

$$
\begin{aligned}
& N_{x_{\text {buckling }}}=\frac{\pi^{2}}{h_{w}^{2}}\left[13.4 \sqrt{D_{11} D_{22}}+10.4\left(D_{12}+2 D_{66}\right)\right](13) \\
& N_{x y_{\text {buckling }}}=\frac{4}{h_{w}^{2}} \sqrt[4]{D_{11} D_{22}^{3}} \\
& (8.125+5.045 K) \quad \text { if } K \leq 1 \text { (14) } \\
& N_{x y_{\text {buckling }}}=\frac{4}{h_{w}^{2}} \sqrt{D_{22}\left(D_{12}+2 D_{66}\right)} \\
& \left(11.7+\frac{1.46}{K^{2}}\right) \text { if } K \geq 1(15)
\end{aligned}
$$

where $K=\left(D_{12}+2 D_{66}\right) / \sqrt{D_{11} D_{22}}$

For flanges:

$$
N_{x_{\text {buckling }}}=\frac{\pi^{2}}{h_{w}^{2}}\left[2 \sqrt{D_{11} D_{22}}+2\left(D_{12}+2 D_{66}\right)\right]
$$

12. Evaluate the cross-section torsional stiffness GJ using the following equation [7], [12]:

$$
G J=\frac{2 A^{2}}{(\mathrm{a}+\mathrm{b})^{2}}\left[\begin{array}{c}
{\left[\mathrm{a}\left(A_{66}-\frac{A_{26}^{2}}{A_{22}}\right)\right]_{w e b}} \\
+\left[\mathrm{b}\left(A_{66}-\frac{A_{26}^{2}}{A_{22}}\right)\right]_{\text {flange }}
\end{array}\right]
$$

13. Find the volume of the plies and their weight per unit length.

\section{VAlidAtion OF COMPOSITE StRUCTURE MOdUle (CSM) WITH ANSYS}

The structure module has been validated with a high order commercial package (ANSYS). A cantilever beam was used as a rectangular wing-box and fixed at one of its ends while at the other end, it is subjected two types of loads which are bending with shear force and pure torsion as shown in Fig. 6. A symmetric stacking laminate is used on each side of the rectangular cross-section. One $\mathrm{mm}$ thick epoxy carbon UD 230GPa Prepreg laminate are used and stacked symmetrically about each mid-plane of each wall. The objective here is to verify the result of the present structure module represented by the highest stresses, the vertical deflections, and the twisting under the three type of loads by comparing the result with those produced by ANSYS.

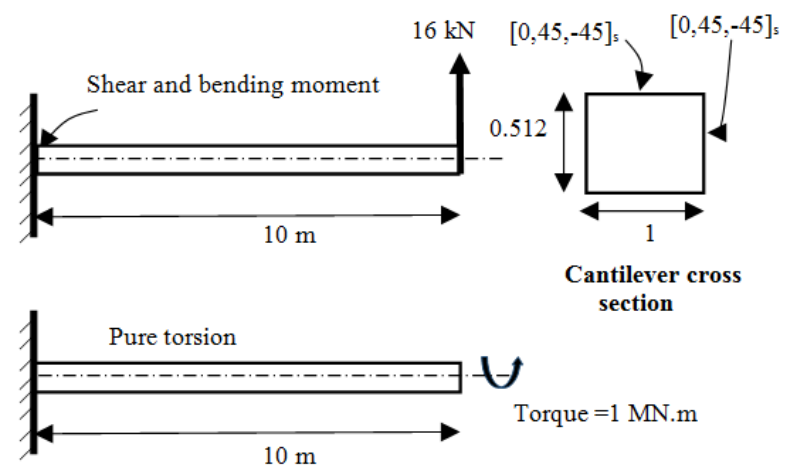

Figure 6. Fixed cantilever wing-box subjected to shear-bending and pure torsion

There has been good agreement so far. Table I shows that the vertical deflection of the beam is underestimated with $0.17 \%$ error while the twist is overestimated with $0.26 \%$ error. The stresses at the critical zones also show an acceptable agreement with errors between $1.29 \%$ and $4.33 \%$. This is usually expected with low order modelling when several assumptions to simplify the calculation are adopted. In general, a composite aircraft structure is designed with a higher factor of safety (more than 3 ) than in a typical metallic structure (about 1.5) [13]. Therefore, the error could be ignored while a relatively higher factor of safety is used. Even with a high factor of safety, the composite material still offers a saving in the weight [13]. 
TABLE I. VALIDATION RESULTS

\begin{tabular}{|c|c|c|c|}
\hline Results & $\begin{array}{c}\text { Present } \\
\text { Model }\end{array}$ & ANSYS & Error \\
\hline \multicolumn{4}{|c|}{ Shear + Bending } \\
\hline Vertical Deflection $(\mathrm{cm})$ & 11.50 & 11.52 & $0.17 \%$ \\
\hline $\begin{array}{l}\text { Maximum Principle Stress (MPa) } \\
\text { At corner of flange ( } 0 \text { plies have the } \\
\text { higher value) }\end{array}$ & 104.32 & 102.99 & $1.29 \%$ \\
\hline $\begin{array}{l}\text { Maximum shear stress }(\mathrm{MPa}) \\
\text { At top of web }( \pm 45 \text { plies that have } \\
\text { the highest value })\end{array}$ & 5.180 & 5.3 & $0.93 \%$ \\
\hline \multicolumn{4}{|c|}{$\begin{array}{ll} & \text { Pure Torsion }\end{array}$} \\
\hline Twist Deflection (degrees) & 12.582 & 12.549 & $0.26 \%$ \\
\hline $\begin{array}{l}\text { Maximum Principle Stress (MPa) } \\
\text { At the flange ( } 45 \text { plies have the } \\
\text { highest value) }\end{array}$ & 439.2 & 459.1 & $4.33 \%$ \\
\hline $\begin{array}{l}\text { Maximum shear stress (MPa) } \\
\text { at middle of web ( } 0 \text { plies have the } \\
\text { highest value) }\end{array}$ & 34.6 & 34.06 & $1.58 \%$ \\
\hline
\end{tabular}

\begin{tabular}{|l|l|l|l|}
\hline \multicolumn{3}{|c|}{ Specifications } \\
\hline \hline \multicolumn{3}{|c|}{ Aspect Ratio } & 12.375 \\
\hline Length (m) & 3.6 & Payload (kg) & Up to 45 \\
\hline Wingspan (m) & 29.5 & $\begin{array}{l}\text { Speed at } 18.3 \mathrm{~km} \\
\text { altitude (m/s) }\end{array}$ & 28.65 \\
\hline $\begin{array}{l}\text { Max. Take-off } \\
\text { weight (kg) }\end{array}$ & 252 & Aerofoil name & LA2573A \\
\hline Chord (m) & 2.438 & $\begin{array}{l}\text { Solar cell area } \\
\text { ratio (\%) }\end{array}$ & 75 \\
\hline $\begin{array}{l}\text { Power for each } \\
\text { motor (kW) }\end{array}$ & 1.5 & & \\
\hline
\end{tabular}

Figure 7. NASA Pathfinder UAV [15]

\section{CASE STUdY}

In order to verify the composite structure modelling, an aircraft baseline configuration is used similar to the Pathfinder high altitude UAV. Its configuration and specifications are shown in Fig. 7. Since there is insufficient detail available for its structure and the weight of some of the elements, the missing weights are estimated as the following:

1- Estimate the structure weight using Rizzo structure mass estimation model which was obtained by data published for the NASA prototypes for HALE UAV [14]:

$$
m_{a f}=1.548 b^{1.312} A R^{-0.0046}
$$

2- Estimate the weight of the non-spar elements by using the empirical equations in section II-A.

3- Estimate the solar cell weight.

4- Estimate the propulsion system weight by using the following equation:

$$
\text { Mass of each motor }=\mathrm{K}_{\text {prop x }} \text { Power }{ }_{\text {of each motor }}
$$

where $\mathrm{K}_{\text {prop }}=0.004 \mathrm{~kg} / \mathrm{W}$ [14].

5- Evaluate the other weights such as the weight of the batteries, the avionics and other inboard elements by subtracting the known weight from the total weight.

It is expected that this weight distribution cannot describe precisely the real model, but this could be a possible way to verify that the structure module can givea reasonable estimation. The weight distribution of the baseline aircraft is as detailed in Table II.

TABLE II. ESTIMATED WEIGHT DISTRIBUTION FOR PATHFINDER UAV

\begin{tabular}{|l|l|}
\hline Structure weight by using Rizzo model & $129.76 \mathrm{~kg}$ \\
\hline Ribs Mass & $13.44 \mathrm{~kg}$ \\
\hline Leading edge mass & $18.98 \mathrm{~kg}$ \\
\hline Trailing edge mass & $3.02 \mathrm{~kg}$ \\
\hline Covering mass & $31.25 \mathrm{~kg}$ \\
\hline Non-spar elements weight & $66.7 \mathrm{~kg}$ \\
\hline Spar weight (Structure weight-non spar weight) & $63.06 \mathrm{~kg}$ \\
\hline Solar cell weight (if $\left.\rho_{\text {solar cell }}=0.365 \mathrm{~kg} / \mathrm{m}^{2}\right)$ & $19.7 \mathrm{~kg}$ \\
\hline Mass of each motor & $6.75 \mathrm{~kg}$ \\
\hline Mass of other components & $62.04 \mathrm{~kg}$ \\
\hline
\end{tabular}

The objective now is to design a wing-box which corresponding to the baseline aircraft for the given configuration and flight state. This is done with the following assumption:

1- The flight condition with a global load factor 3 and safety margin 3 are considered in the sizing process.

2- The wing-box is discretised into ten stations.

3- Payload and other weight factors are considered in inertia relief.

4- There is no dihedral or twist in the wing.

5- Other components (mentioned in Table II) are located at the pods.

6- Aircraft cruise angle of attack is set at 6.5 degrees and the altitude at $18 \mathrm{~km}$.

7- Each lamina has the same mechanical properties as that of epoxy carbon T800/M18 [3].

8- The elastic axis of the wing-box is the same as the quarter chord axis.

9- The wing-box height is equal to 0.8 of the maximum aerofoil thickness and its width is half the height.

\section{A. Result of Sizing}

The given wing configurations are performed in Tornado VL to evaluate the critical load forces in each station. These loading cases are represented by forces relating to the bending moment, the shear force and the torsion (see Fig. 8) to be used in the sizing process. Sizing results has been given by finding the plies stacking sequence in each station to withstand the load. The final sequence is detailed in Table III. The wing-box deflection at the critical aerodynamic load is shown in Fig. 8. The estimated weight has shown a good agreement with the weight estimated by the analytical mass model with $1.6 \%$ difference as follows:

\begin{tabular}{lccc}
\hline & CSM & Baseline UAV & Different \\
\hline Structure weight & 131.93 & 129.76 & $1.6 \%$ \\
\hline
\end{tabular}

\begin{tabular}{|c|c|c|}
\hline Station & Stacking at flanges & Stacking at webs \\
\hline $1-3$ & {$\left[\begin{array}{lll}0_{10} \pm 45_{9}\end{array}\right] \mathrm{s}$} & {$\left[ \pm 45_{6}\right] \mathrm{s}$} \\
\hline $4-5$ & {$\left[0_{10} \pm 45_{9}\right] \mathrm{s}$} & {$\left[ \pm 45_{5}\right] \mathrm{s}$} \\
\hline $6-7$ & {$\left[\begin{array}{ll}0_{9} & \pm 45_{9}\end{array}\right] \mathrm{s}$} & {$\left[ \pm 45_{5}\right] \mathrm{s}$} \\
\hline 8 & {$\left[\begin{array}{ll}0_{8} & \pm 45_{7}\end{array}\right] \mathrm{s}$} & {$\left[ \pm 45_{4}\right] \mathrm{s}$} \\
\hline 9 & {$\left[\begin{array}{ll}0_{8} & \pm 45_{7}\end{array}\right] \mathrm{s}$} & {$\left[ \pm 45_{4}\right] \mathrm{s}$} \\
\hline 10 & {$\left[\begin{array}{ll}0_{6} & \pm 45_{5}\end{array}\right] \mathrm{s}$} & {$\left[ \pm 45_{3}\right] \mathrm{s}$} \\
\hline
\end{tabular}

TABLE III. Plies Stacking In Each Wing-box Station 

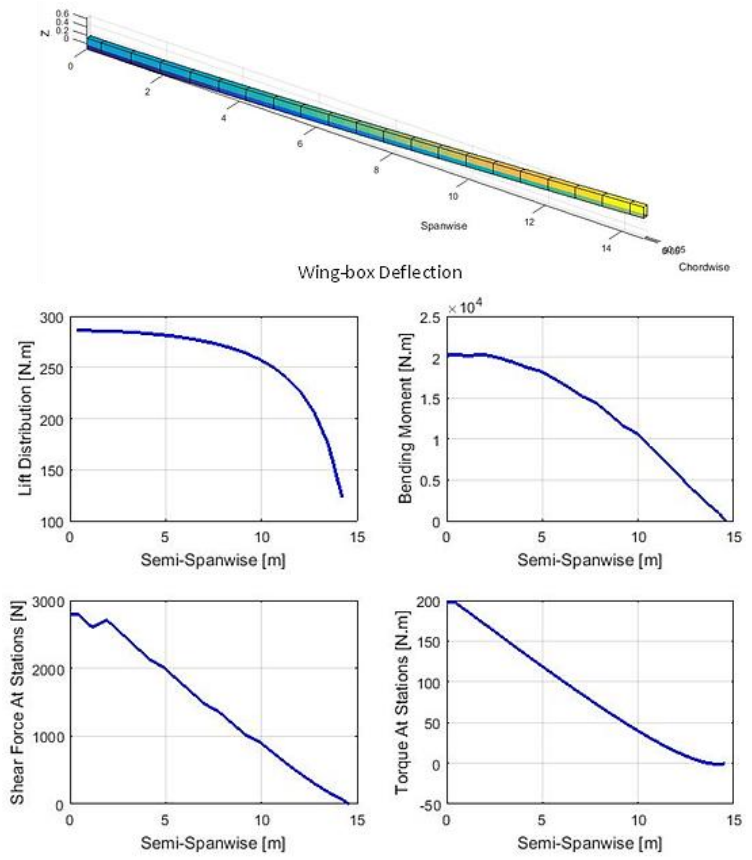

Figure 8. The criticalload distributions and wing-box deflection

\section{CONCLUSIONS}

This low order model has proved that it is capable of providing good accuracy in terms of deflections and stresses. Moreover the weight estimation also showed a reasonable prediction with the baseline aircraft case study. This tool can be used either in the preliminary design stage or during an optimisation process because it facilitates rapid computation.

\section{REFERENCES}

[1] C. E. Cesnik, et al., "X-HALE: A very flexible uav for nonlinear aeroelastic tests," Paper No. AIAA-2010-2715, Proceedings of 2010, 2010

[2] W. L. Ko, W. Richards, and V. T. Tran, "Displacement theories for in-flight deformed shape predictions of aerospace structures," National Aeronautics and Space Administration (NASA), 2007. 214612.

[3] O. Montagnier and L. Bovet, "Optimisation of a solar-powered high altitude long endurance UAV," in Proc. 27th International Congress of The Aeronautical Sciences, Nice, France, 2010.

[4] A. J. Colozza, "Effect of power system technology and mission requirements on high altitude long endurance aircraft," Sverdup Technology Inc., NASA Lewis Group, 1993.

[5] D. W. Hall and S. A. Hall, "Structural sizing of a solar powered aircraft," N.C.R. Lockheed Missiles and Space Company, 1984.

[6] V. V. Vasiliev and E. Morozov, Advanced Mechanics of Composite Materials And Structural Elements, Newnes, 2013.
[7] M. H. Datoo, Mechanics of Fibrous Composites, Springer Science \& Business Media, 2012.

[8] T. H. G. Megson, Aircraft Structures For Engineering Students, Elsevier, 2012.

[9] R. F. Gibson, Principles of Composite Material Mechanics, CRC Press, 2011.

[10] G. Tarján, A. Sapkás, and L. Kollár, "Local buckling of composite beams," Journal of Reinforced Plastics and Composites, 2009.

[11] G. Romeo, F. Danzi, and E. Cestino, "Multi-objective optimization of the composite wing box of solar powered HALE UAV," in Proc. $29^{\text {th }}$ Congress of International Council of the Aeronautical Sciences, St. Petersburg, Russia, 2014.

[12] G. Canale, "Aeroelastic tailoring of aeroplane wings using composite laminates," Department of Aerospace Engineering, University of Bristol, 2010.

[13] A. T. S. Bureau, Fibre Composite Aircraft-Capability and Safety, Australian Transport Safety Bureau, 2008.

[14] E. Rizzo and A. Frediani, "A model for solar powered aircraft preliminary design," The Aeronautical Journal, pp. 57-87, Feb. 2008.

[15] NASA. [Online]. Available: https://www.nasa.gov/

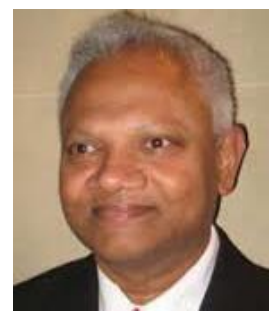

Thurai Rahulan obtained his first degree in Mechanical Engineering Science in 1979 and $\mathrm{PhD}$ in 1984 from the University of Salford. $\mathrm{He}$ commenced full time employment in March 1983 designing aircraft control systems funded by the Ministry of Defence followed by a few years developing advanced suspension systems at Jaguar Cars Limited in Coventry. He started as a Lecturer in Aeronautics in 1990 at the University of Salford. His research interests are inair accident investigation, uninhabited air vehicles, and flight safety.

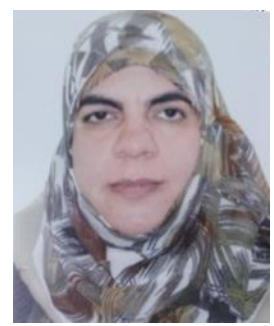

Nathera A. Saleh was born in Basrah - Iraq. She received her degree in Mechanical Engineering (Applied Mechanics); B.Sc in 1993, M.Sc. in 1996, and PhD in Mechanical Engineering (Applied MechanicsBiomechanics) from Basrah University/ Engineering College in 2006. She is currently an Associate Professor at the Mechanical Engineering Department, Basrah University to teach and supervise undergraduate, M.Sc. and $\mathrm{PhD}$ students. Dr. Saleh research interests are fracture mechanics, vibration, buckling, composite material, biomechanics and finite element method.

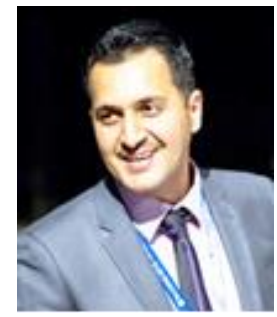

Ahmad Alsahlaniwas born in Basrah southern Iraq. He obtained his BSc and MSc degrees in mechanical engineering from Basrah University in 2004 and 2009 respectively. MrAlsahlani commenced his $\mathrm{PhD}$ study in University of Salford / UK in 2014. His study interest is the design challenges of high altitude, long endurance, and solar powereduninhabited air vehicles. 